\title{
A Real World Report on Intravenous High-Dose and Non-High-Dose Proton-Pump Inhibitors Therapy in Patients with Endoscopically Treated High-Risk Peptic Ulcer Bleeding
}

\author{
Lung-Sheng Lu, Sheng-Chieh Lin, Chung-Mou Kuo, Wei-Chen Tai, Po-Lin Tseng, \\ Kuo-Chin Chang, Chung-Huang Kuo, and Seng-Kee Chuah
} Division of Hepato-Gastroenterology, Department of Internal Medicine and Kaohsiung Chang Gung Memorial Hospital,
College of Medicine, Chang Gung University, 123 Ta-Pei Road, Niaosung Hsiang, Kaohsiung City 833, Taiwan

Correspondence should be addressed to Wei-Chen Tai, luketai1019@gmail.com

Received 13 April 2012; Revised 13 May 2012; Accepted 21 May 2012

Academic Editor: Ping-I Hsu

Copyright (c) 2012 Lung-Sheng Lu et al. This is an open access article distributed under the Creative Commons Attribution License, which permits unrestricted use, distribution, and reproduction in any medium, provided the original work is properly cited.

\begin{abstract}
Background and Study Aims. The optimal dose of intravenous proton-pump inhibitor (PPI) therapy for the prevention of peptic ulcer (PU) rebleeding remains controversial. This study aimed to understand the real world experiences in prescribing high-dose PPI and non-high-dose PPI for preventing rebleeding after endoscopic treatment of high-risk PU. Patients and Methods. A total of 220 subjects who received high-dose and non-high-dose pantoprazole for confirmed acute PU bleeding that were successfully treated endoscopically were enrolled. They were divided into rebleeding $(n=177)$ and non-rebleeding groups $(n=43)$. Randomized matching of the treatment-control group was performed. Patients were randomly selected for non-high-dose and high-dose PPI groups $(n=44$ in each group). Results. Univariate analysis showed, significant variables related to rebleeding were female, higher creatinine levels, and higher Rockall scores $(\geqq 6)$. Before case-control matching, the high-dose PPI group had higher creatinine level, higher percentage of shock at presentation, and higher Rockall scores. After randomized treatment-control matching, no statistical differences were observed for rebleeding rates between the high-dose and non-high-dose groups after casecontrol matching. Conclusion. This study suggests that intravenous high-dose pantoprazole may not be superior to non-high-dose regimen in reducing rebleeding in high-risk peptic ulcer bleeding after successful endoscopic therapy.
\end{abstract}

\section{Introduction}

Patients with high-risk stigmata on endoscopic examination for acute upper gastrointestinal bleeding are at increased risk of recurrent bleeding [1]. Endoscopic hemostasis and continuous infusion intravenous high-dose proton-pumpinhibitor (PPI) have been proven to reduce recurrent bleeding, need for surgery, and length of hospital stay [2, $3]$. Furthermore, the recently updated Vienna consensus states that intravenous high-dose PPI therapy after successful endoscopic hemostasis decreases both peptic ulcer (PU) rebleeding and mortality in patients with high-risk stigmata [4]. Despite these recent advances in the pharmacological and endoscopic treatment of acute nonvariceal upper gastrointestinal hemorrhage, the associated mortality remains high at $10 \%$ to $14 \%$ [5]. Theoretically, inhibiting gastric acid and raising the intragastric $\mathrm{pH}$ to 6 or more and maintaining it at that level may promote clot stability, thus decrease the likelihood of rebleeding. This is based on experimental data showing that gastric acid impairs clot formation, promotes platelet disaggregation, and favors fibrinolysis [6]. The continuous i.v. infusion of pantoprazole $(80 \mathrm{mg}$ bolus plus $8 \mathrm{mg} / \mathrm{h}$ continuous infusion) is able to maintain higher intragastric $\mathrm{pH}$ for $84 \%$ of the time during monitoring, which is higher than intermittent bolus injection $(40 \mathrm{mg}$ every $8 \mathrm{~h}$ ) or lower-dose continuous infusion $(40 \mathrm{mg}$ bolus followed by $4 \mathrm{mg} / \mathrm{h}$ infusion) and hence should attain better control of peptic ulcer bleeding [7]. However, recent systemic review and meta-analysis of this regiment have shown inconsistent results and the optimal dosing of PPI in preventing PU rebleeding remains controversial [8-10]. This retrospective case-controlled study was conducted to 
understand the real world experiences in prescribing highdose PPI and non-high-dose PPI for preventing rebleeding after endoscopic treatment of high-risk PU.

\section{Patients and Methods}

2.1. Patients and Study Design. This is a 2-year retrospective chart review case-control study which began in year 2009. Two hundred and twenty patients with gastric or duodenal ulcers bleeding treated successfully via endoscopy were enrolled into this study. All subjects received intravenous PPIs. We excluded patients with malignant ulcers, upper gastrointestinal bleeding unrelated to peptic ulcer such as angiodysplasia and Mallory-Weiss tear, subjects who lost followup less than the required 30 days for reasons other than mortality, and subjects who were unsuccessfully treated during the first endoscopic hemostasis attempt or received inadequate endoscopic hemostasis therapy for high-risk ulcers such as monotherapy with Bosmin injection alone. This was based on our previous study [11] which emphasized that endoscopic epinephrine injection (EI) monotherapy in patients with high-risk ulcers should be avoided. In current studies, only those patients who received initial hemostasis with epinephrine injection combined with thermal therapy or hemoclips [4], or thermal or clip monotherapy [12] are enrolled. Patient's baseline characteristics, concomitant comorbid diseases (including cardiovascular diseases, stroke, liver cirrhosis, chronic obstructive pulmonary disease, diabetes mellitus, and hypertension), presenting hemoglobin levels, platelet counts, hemodynamic status, use of aspirin, nonsteroidal anti-inflammatory drugs (NSAIDs), warfarin/heparin and PPI prior to endoscopic therapy, were recorded using a predetermined spreadsheet. PU bleeding was defined by endoscopist's diagnosis combined with no other identifiable bleeding cause. Endoscopic findings such as ulcer locations, sizes, difficult treatment sites (lesser curvature of high body; posterior wall of bulb and superior duodenal angle), Forrest grade, Rockall scores [13, 14], and treatment methods were also recorded. The endpoints were rebleeding within 30 days after initial endoscopic hemostasis, requirement for surgical intervention, length of hospital stay and total amount of blood transfusion required, bleedingrelated mortality, and all-cause mortality. According to results from medical record, these patients were classified into two groups: subjects without recurrent hemorrhage $(n=177)$ and those recurred $(n=43)$.

2.2. Definitions. Patients under non-high-dose PPI treatment were defined as those who received $80 \mathrm{mg}$ pantoprazole bolus and followed by i.v. $80 \mathrm{mg}$ per day, until alimentation was possible, then $40 \mathrm{mg}$ per day orally. High-dose PPI therapy were defined as administering $80 \mathrm{mg}$ pantoprazole i.v. bolus injection, then $8 \mathrm{mg}$ per hour continuous infusion for 3 days, followed by i.v. $80 \mathrm{mg}$ per day. Renal function was evaluated by estimated glomerular filtration rate calculated using the 4-variable Modification of Diet in Renal Disease Study equations and classified according to the K/DOQI Clinical Practice Guidelines for Chronic Kidney Disease [15]. High-risk ulcers were defined as Forrest grade higher or equal to $2 b$ [3]. Rebleeding was defined as new onset of hematemesis, coffee-ground vomitus, or hematochezia, with an increasing pulse rate $>110$ beats/min and decreasing blood pressure below $90 \mathrm{mmHg}$ after a 24-hour period of stable vital signs and hematocrit following endoscopic treatment [11, 16-18]. Total amount of blood transfusion required was defined as units given to the patients between the time PU bleeding occurred and the day of discharge. Bleeding-related mortality was defined as in-hospital death resulted solely from peptic ulcer bleeding.

2.3. Statistical Analysis. The quantitative data were compared using the Student's $t$-test for variables with a normal distribution. Differences between the proportions of categorical data were evaluated with Fisher's exact test when the number of expected subjects was less than five and otherwise with the $\chi^{2}$ test. The results are expressed as distributions, absolute frequencies, relative frequencies, medians, and ranges, or means \pm SD. A multivariate logistic regression model was used to assess the independent association between rebreeding and non-rebleeding groups. $P$ value of $<0.05$ was considered statistically significant. The Statistical Package for Social Sciences (SPSS15.0, Chicago, USA) for Windows was used to analyze the data.

We employed the nearest neighbor-matching method (NCSS 2007, Kaysville, Utah 84037, USA) to reduce bias in the retrospective study. The matching algorithm was performed to find one matched control in high-dose PPIs group for each in non-high-dose group. The matching variables were stage of CKD, Forrest classification and Rockall score, and female gender. As a result, forty-four patients were randomly selected in each group.

\section{Result}

The difference between the two study groups (nonrebleeding versus rebleeding groups) was insignificant in terms of age, medication history such as NSAIDs, clopidogrel, warfarin, initial hemoglobin level, platelet counts, shock at presentation, percentage of high stigmata ulcers, ulcer size, and time to endoscope (Table 1). Univariate analysis revealed significant differences in the following variables: gender (female: $28.2 \%$ versus $48.8 \%, P=0.010$ ), initial creatinine level $(2.0 \pm 2.3 \mathrm{mg} / \mathrm{dL}$ versus $3.1 \pm 3.2 \mathrm{mg} / \mathrm{dL}, P<$ $0.00)$, use of aspirin ( $17.5 \%$ versus $2.3 \%, P=0.011)$, CKD stage III to $\mathrm{V}(41.2 \%$ versus $60.5 \%, P=0.013)$, COPD $(3.4 \%$ versus $11.6 \%, P=0.026)$, Rockall score $\geqq 6$ (59.3\% versus $83.7 \%, P=0.003)$, amount of blood transfusion of PRBC $(879.9 \pm 966.4 \mathrm{~mL}$ versus $3220.9 \pm 2824.3 \mathrm{~mL}, P<0.001)$, surgical requirements ( 0 versus $4.7 \%, P=0.004$ ), hospital stay $(10.6 \pm 12.4$ days versus $24.6 \pm 18.6$ days, $P<0.001)$; and mortality $(4.5 \%$ versus $20.9 \%, P=0.001)$. Multivariate analysis showed that the significant factors were sex, high Rockall score, and serum creatinine level (Table 2).

We divided our subjects into two groups: non-high dose and high dose for analysis (Table 3). There were no significant differences between the two groups (nonhigh dose versus high dose) in terms of patients' gender, age, initial hemoglobin and platelet, NSAIDs, aspirin, 
TABLE 1: Univariate analysis of demographic and clinical characteristics of non-rebleeding and rebleeding patients.

\begin{tabular}{|c|c|c|c|}
\hline Variables & Non-rebleeding group $(n=177)$ & Rebleeding group $(n=43)$ & $P$-value \\
\hline Age (years) & $63.4 \pm 13.7$ & $65.2 \pm 13.5$ & 0.941 \\
\hline Female gender, $n(\%)$ & $50(28.2)$ & $21(48.8)$ & $0.010^{*}$ \\
\hline Creatinine $(\mathrm{mg} / \mathrm{dL})$ & $2.0 \pm 2.3$ & $3.1 \pm 3.2$ & $<0.001^{*}$ \\
\hline $\mathrm{Hb}(\mathrm{g} / \mathrm{L})$ & $97.8 \pm 29.4$ & $83.1 \pm 23.4$ & 0.074 \\
\hline Platelet $\left(\times 10^{9} / \mathrm{L}\right)$ & $194.8 \pm 84.1$ & $183.4 \pm 147.5$ & 0.113 \\
\hline Use of NSAIDs, $n(\%)$ & $12(6.8)$ & $2(4.7)$ & 0.608 \\
\hline Use of aspirin, $n(\%)$ & $31(17.5)$ & $1(2.3)$ & $0.011^{*}$ \\
\hline Use of clopidogrel, $n(\%)$ & $18(10.2)$ & $5(11.6)$ & 0.779 \\
\hline Use of warfarin, $n(\%)$ & $7(4.0)$ & $3(7.0)$ & 0.393 \\
\hline \multicolumn{4}{|l|}{ Coexisting illness, $n(\%)$} \\
\hline CKD III to $\mathrm{V}$ & $73(41.2)$ & $26(60.5)$ & $0.013^{*}$ \\
\hline COPD & $6(3.4)$ & $5(11.6)$ & $0.026^{*}$ \\
\hline CAD & $29(16.4)$ & $8(18.6)$ & 0.727 \\
\hline $\mathrm{DM}$ & $48(27.1)$ & $18(41.9)$ & 0.058 \\
\hline CVA & $26(14.7)$ & $8(18.6)$ & 0.524 \\
\hline Liver cirrhosis & $32(18.1)$ & $7(16.3)$ & 0.782 \\
\hline High stigmata, $n(\%)$ & $173(97.7)$ & $41(95.3)$ & 0.388 \\
\hline Forrest classification Ia/Ib/IIa/IIb/IIc/III & $9 / 100 / 18 / 45 / 5 / 0$ & $5 / 31 / 1 / 5 / 0 / 1$ & \\
\hline Shock on admission, $n(\%)$ & $89(50.3)$ & $23(53.5)$ & 0.706 \\
\hline Rockall score $\geqq 6, n(\%)$ & $105(59.3)$ & $36(83.7)$ & $0.003^{*}$ \\
\hline Time to endoscope (h) & $14.3 \pm 17.5$ & $19.9 \pm 20.2$ & 0.129 \\
\hline Hemostasis methods $\mathrm{A} / \mathrm{B} / \mathrm{C} / \mathrm{D} / \mathrm{E} / \mathrm{F}$ & $62 / 48 / 11 / 50 / 2 / 4$ & $11 / 14 / 0 / 15 / 2 / 1$ & \\
\hline Ulcer size $(\mathrm{cm})$ & $1.0 \pm 0.7$ & $0.9 \pm 0.6$ & 0.973 \\
\hline Multiple ulcers, $n(\%)$ & $58(32.8)$ & $18(41.9)$ & 0.261 \\
\hline PRBC BT $(\mathrm{mL})$ & $879.9 \pm 966.4$ & $3220.9 \pm 2824.3$ & $<0.001^{*}$ \\
\hline Surgery, $n(\%)$ & 0 & $2(4.7)$ & $0.004^{*}$ \\
\hline Hospital stay (days) & $10.6 \pm 12.4$ & $24.6 \pm 18.6$ & $<0.001^{*}$ \\
\hline Mortality, $n(\%)$ & $8(4.5)$ & $9(20.9)$ & $0.001^{*}$ \\
\hline Bleeding related/other causes & $1 / 7$ & $3 / 6$ & \\
\hline
\end{tabular}

PPI: proton-pump inhibitors, $\mathrm{Hb}$ : hemoglobin, CKD: chronic kidney disease, NSAID: nonsteroidal anti-inflammatory drug, PPI: proton-pump inhibitor, DM: diabetes mellitus type 2, COPD: chronic obstructive pulmonary disease, CAD: coronary artery disease, CVA: cerebrovascular accident, BT: blood transfusion, PPI: proton pump inhibitor, Hemostasis methods A/B/C/D/E/F: Bosmin plus APC/heat probe=A, APC/heat probe=B, Hemoclip=C, Bosmin plus hemoclip=D, APC/heat probe plus hemoclip=E, APC plus hemoclip plus Bosmin=F, APC: argon plasma coagulation. ${ }^{*} P<0.05$.

TABle 2: Multivariate analysis for rebleeding and nonbleeding patients.

\begin{tabular}{lccc}
\hline & Odds ratio & $95 \%$ CI. & $P$ value \\
\hline Sex & 0.408 & $0.201-0.828$ & 0.013 \\
High Rockall score & 3.215 & $1.324-7.808$ & 0.010 \\
Creatinine & 1.119 & $0.992-1.263$ & 0.066 \\
\hline
\end{tabular}

clopidogrel, warfarin use, Rockall score, ulcer pattern of Forrest, time to endoscope, duration of hospital stay, surgical interventions, rebleeding rate, and mortality. Significant variables were initial creatinine level $(2.0 \pm 2.4 \mathrm{mg} / \mathrm{dL}$ versus $2.6 \pm 2.82 \mathrm{mg} / \mathrm{dL}, P=0.018)$, diabetes $(25.3 \%$ versus $40.0 \%$, $P=0.027)$, CVA (12.0\% versus $22.9 \%, P=0.038)$, and shock at presentation $(46.0 \%$ versus $61.4 \%, P=0.033)$. Although the Rockall score was not significant between these two groups, it was higher in trend in the high-dose group $(5.9 \pm 1.7$ versus $6.3 \pm 1.5, P=0.106)$.
To minimize the clinical characteristics difference between non-high-dose and high-dose groups, we created a treatment-control randomized match based on CKD stages, Forrest classifications, and Rockall scores. Fifty-six patients were randomly selected in each group of non-high- dose and high dose for analysis (Table 4). All of them have high-risk ulcers according to Forrest classification. As a result, there were no significant differences between the two groups (nonhigh dose versus high dose) in all demographic and clinical characteristics such as the rebleeding rate $(18.2 \%$ versus $15.9 \%, P=0.777)$, surgery needed ( 0 versus $0 \%, P=1.000)$, and hospital stay $(12.1 \pm 17.2$ days versus $14.3 \pm 13.5$ days, $P=0.505)$.

\section{Discussion}

After the randomized treatment-control matching process to minimize possible selection bias between the two treatment groups, current retrospective case-controlled study observed 
TABLE 3: Comparison between the non-high-dose and high-dose PPI before case-controlled matching.

\begin{tabular}{|c|c|c|c|}
\hline Characteristic & Non-high-dose group $(n=150)$ & High-dose group $(n=70)$ & $P$-value \\
\hline Age (years) & $64.1 \pm 13.3$ & $62.6 \pm 14.4$ & 0.558 \\
\hline Female gender, $n(\%)$ & $105(70.0)$ & $44(62.9)$ & 0.291 \\
\hline Creatinine $(\mathrm{mg} / \mathrm{dL})$ & $2.0 \pm 2.4$ & $2.6 \pm 2.8$ & $0.018^{*}$ \\
\hline $\mathrm{Hb}(\mathrm{g} / \mathrm{L})$ & $96.2 \pm 28.2$ & $92.1 \pm 30.1$ & 0.438 \\
\hline Platelet $\left(\times 10^{9} / \mathrm{L}\right)$ & $195.2 \pm 103.5$ & $186.8 \pm 90.4$ & 0.592 \\
\hline Use of NSAIDs, $n(\%)$ & $8(5.3)$ & $6(8.6)$ & 0.359 \\
\hline Use of aspirin, $n(\%)$ & $23(15.3)$ & $9(12.9)$ & 0.628 \\
\hline Use of clopidogrel, $n(\%)$ & $15(10.0)$ & $8(11.4)$ & 0.747 \\
\hline Use of warfarin, $n(\%)$ & $5(3.3)$ & $5(7.1)$ & 0.206 \\
\hline \multicolumn{4}{|l|}{ Coexisting illness, $n(\%)$} \\
\hline CKD III, IV/V & $47 / 17(31.3 / 11.3)$ & $23 / 12(32.9 / 17.1)$ & 0.422 \\
\hline COPD & $8(5.3)$ & $3(4.3)$ & 0.740 \\
\hline CAD & $21(14.0)$ & $16(22.6)$ & 0.102 \\
\hline $\mathrm{DM}$ & $38(25.3)$ & $28(40.0)$ & $0.027^{*}$ \\
\hline CVA & $18(12.0)$ & $16(22.9)$ & $0.038^{*}$ \\
\hline Liver cirrhosis & $26(17.3)$ & $13(18.6)$ & 0.321 \\
\hline Forrest classification Ia/Ib/IIa/IIb/IIc/III & $11 / 86 / 12 / 35 / 5 / 1$ & $3 / 45 / 7 / 15 / 0 / 0$ & 0.524 \\
\hline Shock on admission & $69(46.0)$ & $43(61.4)$ & $0.033^{*}$ \\
\hline Rockall score & $5.9 \pm 1.7$ & $6.3 \pm 1.5$ & 0.106 \\
\hline Time to endoscope (hours) & $15.9 \pm 19.2$ & $14.1 \pm 15.8$ & 0.107 \\
\hline Hemostasis methods $\mathrm{A} / \mathrm{B} / \mathrm{C} / \mathrm{D} / \mathrm{E} / \mathrm{F}$ & $11 / 86 / 12 / 35 / 5 / 1$ & $3 / 45 / 7 / 15 / 0 / 0$ & \\
\hline $\operatorname{PRBC} \mathrm{BT}(\mathrm{mL})$ & $11101.7 \pm 1495.3$ & $1842.9 \pm 2185.7$ & 0.196 \\
\hline Multiple ulcers, $n(\%)$ & $50(38.7)$ & $26(37.1)$ & 0.580 \\
\hline Rebleeding, $n(\%)$ & $24(16.0)$ & $19(27.1)$ & 0.052 \\
\hline Surgery, $n(\%)$ & $1(0.6)$ & $1(1.4)$ & 0.579 \\
\hline Hospital stay (days) & $11.9 \pm 14.9$ & $16.5 \pm 14.3$ & 0.343 \\
\hline Mortality, $n(\%)$ & $9(6.0)$ & $8(11.4)$ & 0.207 \\
\hline Bleeding related/other causes & $3 / 6$ & $1 / 7$ & \\
\hline
\end{tabular}

Hb: hemoglobin, NSAID: nonsteroidal anti-inflammatory drug, CKD: chronic kidney disease, PPI: proton-pump inhibitor, DM: diabetes mellitus type 2, COPD: chronic obstructive pulmonary disease, CAD: coronary artery disease, CVA: cerebrovascular accident, BT: blood transfusion, PPI: proton pump inhibitor, Hemostasis methods A/B/C/D/E/F: Bosmin plus APC/heat probe=A, APC/heat probe=B, Hemoclip=C, Bosmin plus hemoclip=D, APC/heat probe plus hemoclip=E, APC plus hemoclip plus Bosmin=F, APC: argon plasma coagulation. ${ }^{*} P<0.05$.

that the continuous high-dose PPI regimen did not appear to be more effective in reducing rebleeding compared to non-high-dose regimen in subjects with high-risk ulcer bleeding after initial endoscopic hemostasis in real world clinical practice $(18.2 \%$ versus $15.9 \%)$ as shown in Table 4. Meta-analysis performed by Wang also found that high-dose PPIs do not further reduce the rates of rebleeding, surgical intervention, or mortality after endoscopic treatment in patients with bleeding peptic ulcer [8]. This is contrary to the recently updated consensus statements on the routine use of the intensive PPI regimen for high-risk ulcer bleeding [4].

The explanation to the high rebleeding rate in the current study $(43 / 220,19.5 \%)$ is possibly due to the inclusion of a higher percentage ulcers with high-risk stigmata (214/220, 97.3\%) and patients with more severe comorbidities (Rockall score: Mean $\pm \mathrm{SD}=6.0 \pm 1.6$ ). In real world practice, more physicians may prescribe high-dose intravenous PPIs in more severe patients. This may also explain the higher rebleeding rate in the high-dose group (27.1\% versus $16.0 \%)$ before case-controlled matching. However, the rebleeding rate were identical after case-controlled matching as shown in Table 4. Although we believe that the evidence from our findings may be supportive of the aforementioned studies regarding the issue that low-dose intravenous PPI dosage may be enough in treating peptic ulcer bleeding, potential bias and the relatively small sample size may hinder the conclusion for the optimal dosing of PPIs for bleeding high risk PU.

The other explanation for the possible lower dosage needed for Taiwanese may be attributed to the metabolism of PPI via the pathway of cytochrome P450 system (CYP), where its influential role was considered substantial in this issue [19]. There are more Caucasians than Asians who belong to homozygous extensive metabolizer (EM) in the distribution of genetic polymorphisms of CYP [20, 21], and the effect to maintain intragastric $\mathrm{pH}>6.0$ in the EM patients with intravenous pantoprazole is inferior to the nonEM patients owing to the lower plasma concentration [22]. Therefore it is rational that this racial difference could suggest 
TABLE 4: Comparison between the non-high-dose and high-dose PPI after case-controlled matching.

\begin{tabular}{|c|c|c|c|}
\hline Characteristic & Non-high-dose group $(n=44)$ & High-dose group $(n=44)$ & $P$ value \\
\hline Age (years) & $66.2 \pm 12.9$ & $61.7 \pm 13.8$ & 0.121 \\
\hline Female gender, $n(\%)$ & $11(25)$ & $12(27.3)$ & 0.808 \\
\hline Creatinine (mg/dL) & $2.3 \pm 2.3$ & $2.6 \pm 2.8$ & 0.615 \\
\hline $\mathrm{Hb}(\mathrm{g} / \mathrm{L})$ & $93.3 \pm 25.3$ & $92.5 \pm 28.7$ & 0.897 \\
\hline Platelet $\left(\times 10^{9} / \mathrm{L}\right)$ & $170.4 \pm 86.2$ & $189.2 \pm 82.1$ & 0.297 \\
\hline Use of NSAIDs, $n(\%)$ & $3(6.8)$ & $2(4.5)$ & 0.696 \\
\hline Use of aspirin, $n(\%)$ & $4(9.1)$ & $5(11.4)$ & 0.725 \\
\hline Use of clopidogrel, $n(\%)$ & $3(6.8)$ & $4(9.1)$ & 0.694 \\
\hline Use of warfarin, $n(\%)$ & $1(2.3)$ & $2(4.5)$ & 0.557 \\
\hline \multicolumn{4}{|l|}{ Coexisting illness, $n(\%)$} \\
\hline CKD III, IV/V & $19 / 6$ & $13 / 7$ & 0.410 \\
\hline COPD & 1 & 0 & 0.315 \\
\hline CAD & 6 & 10 & 0.269 \\
\hline $\mathrm{DM}$ & 12 & 14 & 0.640 \\
\hline CVA & 12 & 7 & 0.195 \\
\hline Liver cirrhosis & 10 & 8 & 0.597 \\
\hline Shock oat presentation & 24 & 28 & 0.386 \\
\hline Rockall score & $6.1 \pm 1.4$ & $6.4 \pm 1.5$ & 0.387 \\
\hline Time to endoscope (hours) & $18.3 \pm 23.9$ & $13.6 \pm 17.2$ & 0.299 \\
\hline PRBC BT $(\mathrm{mL})$ & $1369.3 \pm 1496.5$ & $1596.6 \pm 1914.0$ & 0.537 \\
\hline Forrest classification Ia/Ib/IIa/IIb/IIc/III & $2 / 28 / 1 / 13$ & $1 / 28 / 4 / 11$ & 0.513 \\
\hline Time to oral PPI (days) & $4.5 \pm 4.4$ & $6.9 \pm 4.8$ & $0.016^{*}$ \\
\hline Rebleeding, $n(\%)$ & $8(18.2)$ & $7(15.9)$ & 0.777 \\
\hline Surgery, $n(\%)$ & 0 & 0 & 1.000 \\
\hline Hospital stay (days) & $12.1 \pm 17.2$ & $14.3 \pm 13.5$ & 0.505 \\
\hline Mortality, $n(\%)$ & $5(11.4)$ & $3(6.8)$ & 0.359 \\
\hline Bleeding related/other causes & $3 / 2$ & $3 / 0$ & \\
\hline
\end{tabular}

Hb: hemoglobin, NSAID: nonsteroidal anti-inflammatory drug, CKD: chronic kidney disease, PPI: proton-pump inhibitor, DM: diabetes mellitus type 2, COPD: chronic obstructive pulmonary disease, CAD: coronary artery disease, CVA: cerebrovascular accident, BT: blood transfusion, PPI: proton-pump inhibitor, Hemostasis methods A/B/C/D/E/F: Bosmin plus APC/heat probe=A, APC/heat probe=B, Hemoclip=C, Bosmin plus hemoclip=D, APC/heat probe plus hemoclip=E, APC plus hemoclip plus Bosmin=F, APC: argon plasma coagulation. ${ }^{*} P<0.05$.

that PPI should have better effect in Taiwanese patients $[23,24]$.

In our study we observed that CKD stage III to $\mathrm{V}$ was the independent risk factor for recurrent bleeding. This is despite the fact that all ESRD subjects received heparin-free dialysis in our hospital. Our findings were consistent with $\mathrm{Wu}$ et al. [25] and Cheung et al. [26] who reported that patients with ESRD and advanced chronic kidney disease were at higher risk of peptic ulcer rebleeding. The mechanism for the excessive bleeding in patients with ESRD is still unclear but may be multifactorial [27]. Platelet dysfunction in the form of impaired platelet adhesiveness and altered platelet-vesselwall interaction is believed to have played an important role [28]. Furthermore this platelet dysfunction is not normalized after dialysis [29, 30]. The female gender in our study had higher rebleeding rate before case-controlled matching. This is probably by chance or perhaps, the study number was not big enough, and we need larger study scale to minimize the bias. However, when we re-analyzed the casematching between the high-dose and non-high-dose groups, this problem does not exist anymore.
We recognized several limitations in this study. First, this retrospective analysis depended heavily on the completeness of the medical charts. If incomplete chart description of ulcer morphology was encountered, we would review endoscopic images or videos to determine the location and severity of the ulcer involved. Second, the selection bias may exist in highdose group caused by clinicians' decision on PPI dosage in patients with more severe diseases or with less manageable bleeding ulcers. One of the main purposes of the study was to attempt to minimize selection bias by the randomized treatment-control matching process after controlling the baseline conditions of subjects. Although we observed that the rebleeding rates were identical in high-dose and nonhigh-dose patients after case-controlled matching, the case number was too small for a solid conclusion.

In conclusion, this study suggests that the effect of intravenous high-dose pantoprazole may not be superior to non-high dose regimen in reducing the occurrence of rebleeding, mortality rate, and surgery needed in patients in high-risk peptic ulcer bleeding after successful endoscopic hemostasis. More large scale prospective studies to clarify the 
issue are still mandatory. In real world practice, election bias may exist in high-dose group caused by clinicians' decision on PPI dosage in patients with more severe diseases or with less manageable bleeding ulcers.

\section{References}

[1] M. L. Freeman, O. W. Cass, C. J. Peine, and G. R. Onstad, “The non-bleeding visible vessel versus the sentinel clot: natural history and risk of rebleeding," Gastrointestinal Endoscopy, vol. 39, no. 3, pp. 359-366, 1993.

[2] J. Y. W. Lau, J. J. Y. Sung, K. K. C. Lee et al., "Effect of intravenous omeprazole on recurrent bleeding after endoscopic treatment of bleeding peptic ulcers," The New England Journal of Medicine, vol. 343, no. 5, pp. 310-316, 2000.

[3] I. M. Gralnek, A. N. Barkun, and M. Bardou, "Management of acute bleeding from a peptic ulcer," The New England Journal of Medicine, vol. 359, no. 9, pp. 928-937, 2008.

[4] A. N. Barkun, M. Bardou, E. J. Kuipers et al., "International consensus recommendations on the management of patients with nonvariceal upper gastrointestinal bleeding," Annals of Internal Medicine, vol. 152, no. 2, pp. 101-113, 2010.

[5] M. E. van Leerdam, E. M. Vreeburg, E. A. J. Rauws et al., "Acute upper GI bleeding: did anything change? Time trend analysis of incidence and outcome of acute upper GI bleeding between 1993/1994 and 2000," American Journal of Gastroenterology, vol. 98, no. 7, pp. 1494-1499, 2003.

[6] A. N. Barkun, A. W. Cockeram, V. Plourde, and R. N. Fedorak, "Review article: acid suppression in non-variceal acute upper gastrointestinal bleeding," Alimentary Pharmacology and Therapeutics, vol. 13, no. 12, pp. 1565-1584, 1999.

[7] G. Brunner, P. Luna, M. Hartmann, and W. Wurst, "Optimizing the intragastric $\mathrm{pH}$ as a supportive therapy in upper GI bleeding," Yale Journal of Biology and Medicine, vol. 69, no. 3, pp. 225-231, 1996.

[8] C. H. Wang, M. H. M. Ma, H. C. Chou et al., "High-dose vs non-high-dose proton pump inhibitors after endoscopic treatment in patients with bleeding peptic ulcer: a systematic review and meta-analysis of randomized controlled trials," Archives of Internal Medicine, vol. 170, no. 9, pp. 751-758, 2010.

[9] A. Andriulli, S. Loperfido, R. Focareta et al., "High- versus low-dose proton pump inhibitors after endoscopic hemostasis in patients with peptic ulcer bleeding: a multicentre, randomized study," American Journal of Gastroenterology, vol. 103, no. 12, pp. 3011-3018, 2008.

[10] H. C. Cheng, A. W. Kao, C. H. Chuang, and B. S. Sheu, "The efficacy of high- and low-dose intravenous omeprazole in preventing rebleeding for patients with bleeding peptic ulcers and comorbid illnesses," Digestive Diseases and Sciences, vol. 50, no. 7, pp. 1194-1201, 2005.

[11] M. L. Hu, K. L. Wu, K. W. Chiu et al., "Predictors of rebleeding after initial hemostasis with epinephrine injection in high-risk ulcers," World Journal of Gastroenterology, vol. 16, no. 43, pp. 5490-5495, 2010.

[12] R. Marmo, G. Rotondano, R. Piscopo, M. A. Bianco, R. D'Angella, and L. Cipolletta, "Dual therapy versus monotherapy in the endoscopic treatment of high-risk bleeding ulcers: a meta-analysis of controlled trials," American Journal of Gastroenterology, vol. 102, no. 2, pp. 279-289, 2007.

[13] T. A. Rockall, R. F. A. Logan, H. B. Devlin, and T. C. Northfield, "Risk assessment after acute upper gastrointestinal haemorrhage," Gut, vol. 38, no. 3, pp. 316-321, 1996.
[14] N. I. Church, H. J. Dallal, J. Masson et al., "Validity of the Rockall scoring system after endoscopic therapy for bleeding peptic ulcer: a prospective cohort study," Gastrointestinal Endoscopy, vol. 63, no. 4, pp. 606-612, 2006.

[15] National Kidney Foundation, "K/DOQI clinical practice guidelines for chronic kidney disease: evaluation, classification, and stratification," American Journal of Kidney Diseases, vol. 39, no. 2, supplement 1, pp. S1-S266, 2002.

[16] H. W. Xu, J. H. Wang, M. S. Tsai et al., "The effects of cefazolin on cirrhotic patients with acute variceal hemorrhage after endoscopic interventions," Surgical Endoscopy, vol. 25, no. 9, pp. 2911-2918, 2011.

[17] S. C. Lin, K. L. Wu, K. W. Chiu et al., "Risk factors influencing the outcome of peptic ulcer bleeding in end stage renal diseases after initial endoscopic haemostasis," International Journal of Clinical Practice. In press.

[18] S. C. Yang, K. L. Wu, J. H. Wang et al., "The effect of systemic antibiotic prophylaxis for cirrhotic patients with peptic ulcer bleeding after endoscopic interventions," Hepatology International. In press.

[19] J. M. Kang, N. Kim, D. H. Lee et al., "Effect of the CYP2C19 polymorphism on the eradication rate of Helicobacter pylori infection by 7 -day triple therapy with regular proton pump inhibitor dosage," Journal of Gastroenterology and Hepatology, vol. 23, no. 8, pp. 1287-1291, 2008.

[20] T. Furuta, N. Shirai, M. Sugimoto, A. Nakamura, A. Hishida, and T. Ishizaki, "Influence of CYP2C19 pharmacogenetic polymorphism on proton pump inhibitor-based therapies," Drug Metabolism and Pharmacokinetics, vol. 20, no. 3, pp. 153167, 2005.

[21] P. W. Y. Lim, K. L. Goh, and B. C. Y. Wong, "CYP2C19 genotype and the PPIs-focus on rabeprazole," Journal of Gastroenterology and Hepatology, vol. 20, no. 3, supplement, pp. S22-S28, 2005.

[22] J. H. Oh, M. G. Choi, M. S. Dong et al., "Low-dose intravenous pantoprazole for optimal inhibition of gastric acid in Korean patients," Journal of Gastroenterology and Hepatology, vol. 22, no. 9, pp. 1429-1434, 2007.

[23] L. Bertilsson, "Geographical/interracial differences in polymorphic drug oxidation. Current state of knowledge of cytochromes P450 (CYP) 2D6 and 2C19," Clinical Pharmacokinetics, vol. 29, no. 3, pp. 192-209, 1995.

[24] B. S. Sheu, A. W. Kao, H. C. Cheng et al., "Esomeprazole $40 \mathrm{mg}$ twice daily in triple therapy and the efficacy of Helicobacter pylori eradication related to CYP2C19 metabolism," Alimentary Pharmacology and Therapeutics, vol. 21, no. 3, pp. 283288, 2005.

[25] C. Y. Wu, M. S. Wu, K. N. Kuo, C. B. Wang, Y. J. Chen, and J. T. Lin, "Long-term peptic ulcer rebleeding risk estimation in patients undergoing haemodialysis: a 10-year nationwide cohort study," Gut, vol. 60, no. 8, pp. 1038-1042, 2011.

[26] J. Cheung, A. Yu, J. LaBossiere, Q. Zhu, and R. N. Fedorak, "Peptic ulcer bleeding outcomes adversely affected by endstage renal disease," Gastrointestinal Endoscopy, vol. 71, no. 1, pp. 44-49, 2010.

[27] A. B. Toke, "GI bleeding risk in patients undergoing dialysis," Gastrointestinal Endoscopy, vol. 71, no. 1, pp. 50-52, 2010.

[28] P. Boccardo, G. Remuzzi, and M. Galbusera, "Platelet dysfunction in renal failure," Seminars in Thrombosis and Hemostasis, vol. 30, no. 5, pp. 579-589, 2004.

[29] R. Sreedhara, I. Itagaki, B. Lynn, and R. M. Hakim, "Defective platelet aggregation in uremia is transiently worsened by hemodialysis," American Journal of Kidney Diseases, vol. 25, no. 4, pp. 555-563, 1995. 
[30] G. Remuzzi, M. Livio, and G. Marchiaro, "Bleeding in renal failure: altered platelet function in chronic uraemia only partially corrected by haemodialysis," Nephron, vol. 22, no. 46, pp. 347-353, 1978. 


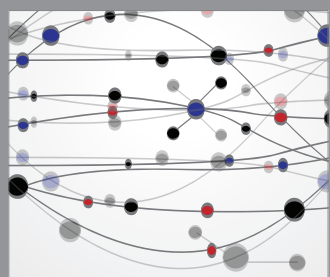

The Scientific World Journal
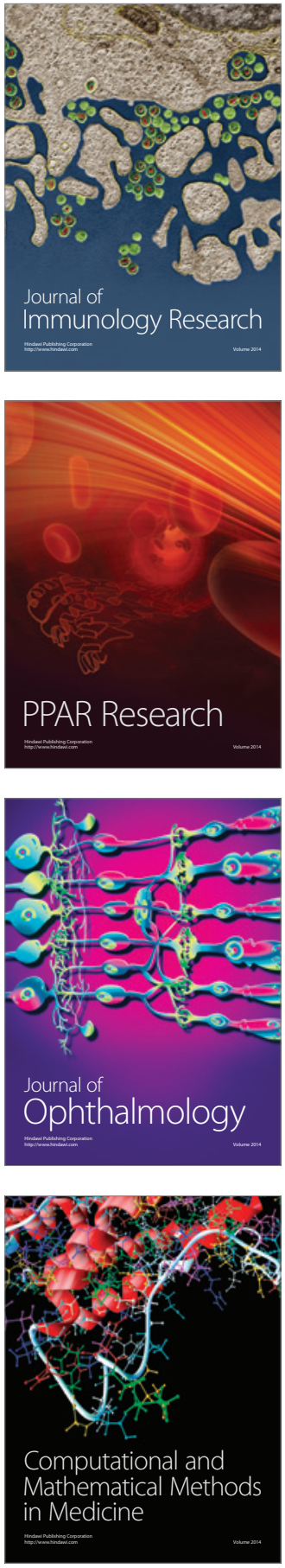

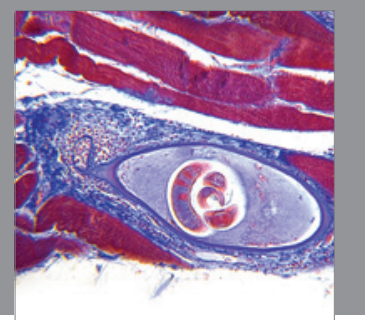

Gastroenterology

Research and Practice
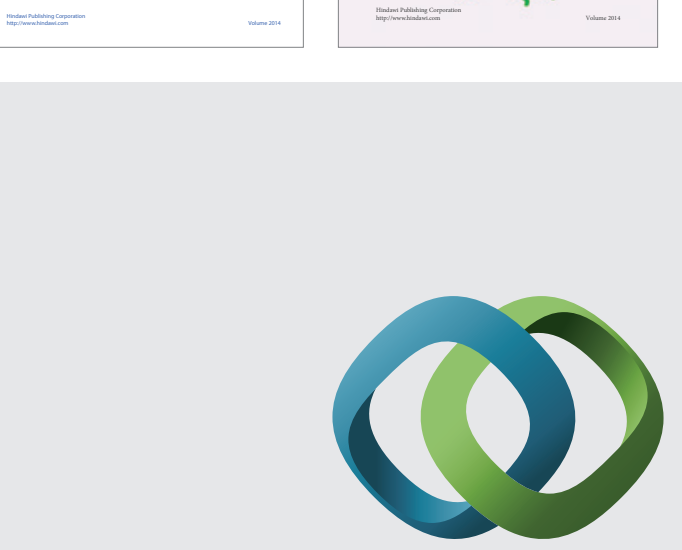

\section{Hindawi}

Submit your manuscripts at

http://www.hindawi.com
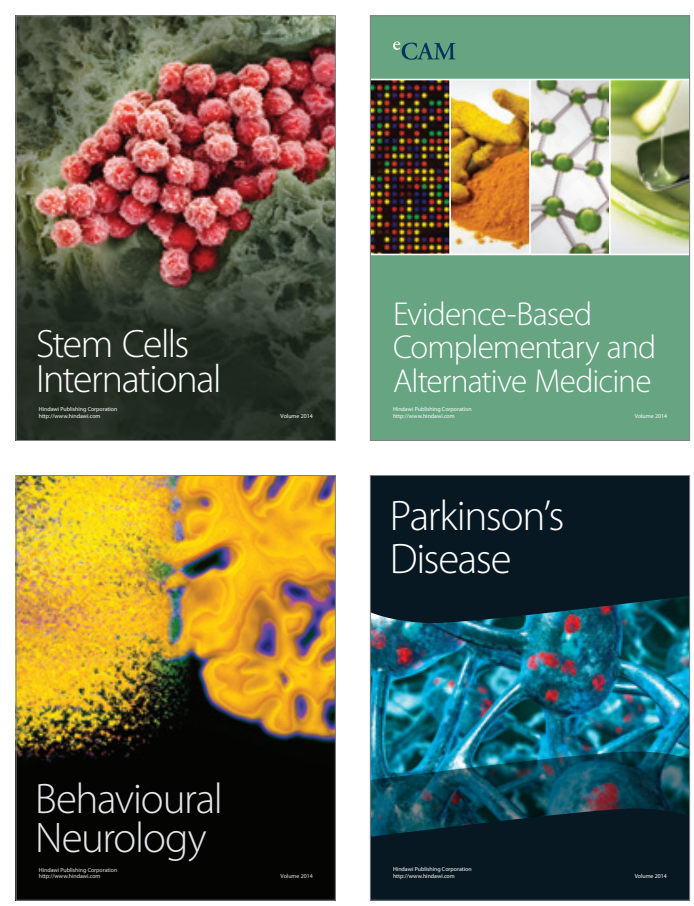

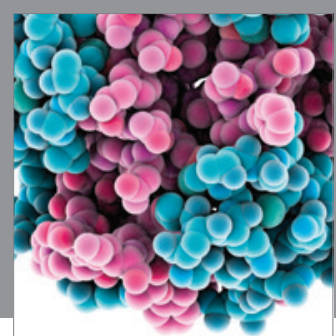

Journal of
Diabetes Research

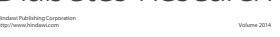

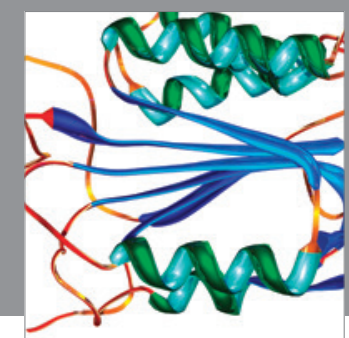

Disease Markers
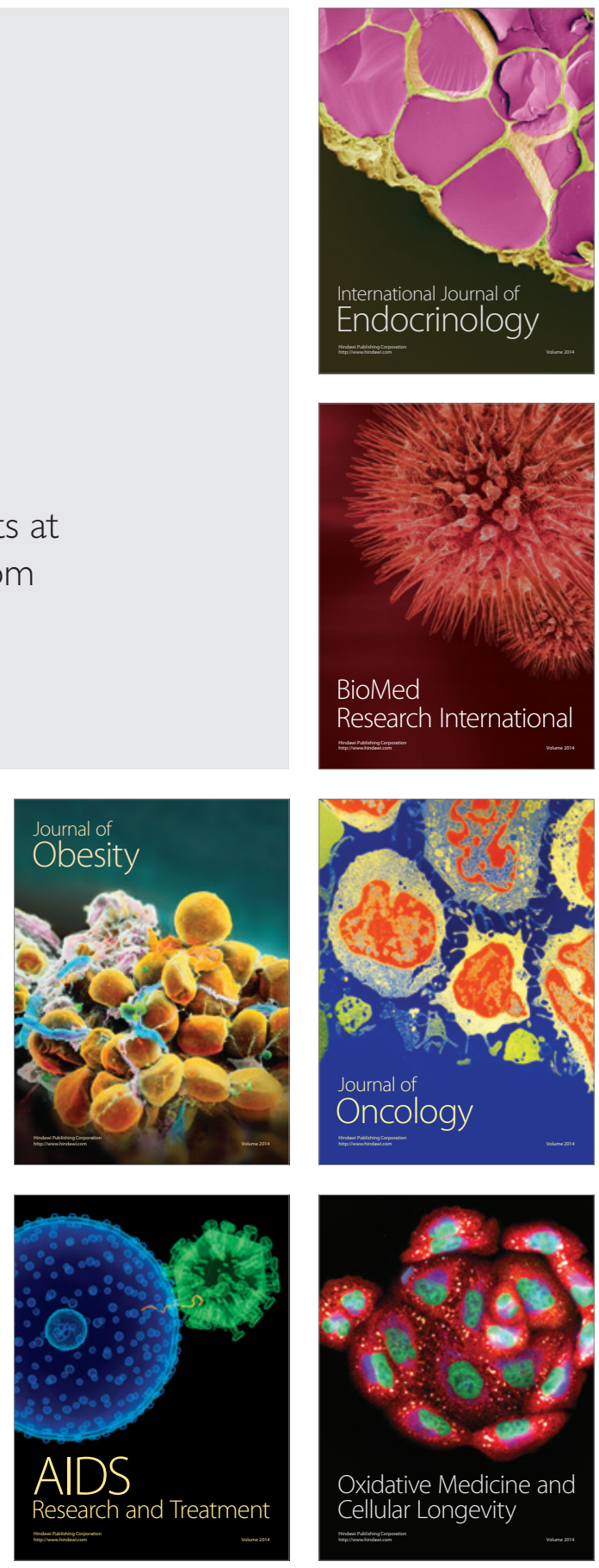